\title{
Gênero como Performance: a Participação Feminina na Política de Ruanda
}

\author{
Tatiane Souza de Albuquerque ${ }^{1}$
}

\begin{abstract}
Resumo
Depois do conhecido genocídio de 1994 em Ruanda, o país atualmente vem ganhando visibilidade nas discussões sobre representatividade feminina devido aos seus indicadores positivos de igualdade de gênero. Por meio das perspectivas feministas das Relações Internacionais, o debate sobre gênero nos países africanos vem ganhando espaço. Após realizar análises de documentos oficiais de Ruanda, artigos acadêmicos, livros e demais fontes eletrônicas, foi possível perceber que, ainda que o país seja mais conhecido no meio internacional pelo recente conflito, Ruanda tem se recuperado por meio de iniciativas que partem desde mudanças na estrutura política até os movimentos que partem da iniciativa social local. Nesse sentido, as mulheres são peças fundamentais para a reconstrução do país, contribuindo por meio do peacebuilding que é incentivado em diferentes órgãos de tomada de decisão e outras organizações civis. Tal fato gerou uma série de discussões acerca do tema 'gênero', abarcando pensamentos teóricos pós coloniais e feministas das Relações Internacionais. Com isso, o presente artigo irá analisar a atuação das mulheres em Ruanda, levantando questões sobre as noções de democracia no país e a importância da implementação de políticas de incentivo como meio de se promover a igualdade de gênero.
\end{abstract}

Palavras-chave: Ruanda, empoderamento feminino, participação política.

\begin{abstract}
Following the 1994 genocide in Rwanda, the country has been gaining visibility in the discussions on female representativeness and its positive indicators of gender equality. From the African and feminist perspectives of International Relations, the gender debate in African countries has gained more prominence. After performing documentary analyses of Rwanda's official texts, academic articles, books and other electronic sources, it is possible to realize that, although the country is internationally known due to the recent conflict, Rwanda has recovered through initiatives starting from changes in the political structure to local social movements. In this sense, women are key pieces in the reconstruction of the country, and contribute through peacebuildingwhich is encouraged by different decision-making bodies and other civil organizations. This fact has generated discussions about 'gender', encompassing postcolonial and feminist theories of International Relations. This monograph will analyse the participation of women in Rwanda, raising questions about democracy in the country and the importance of incentive policies implementation as a means to promote gender equality.
\end{abstract}

Key Words: Rwanda, women's empowerment, political participation.

\footnotetext{
${ }^{1}$ Aluna de graduação de Relações Internacionais pela Universidade Federal da Paraíba (UFPB).
} 


\section{Introdução}

Depois de ter sido palco de um dos piores genocídios da história há pouco mais de vinte anos, desta vez Ruanda vem se destacando por um ponto positivo: a participação das mulheres na política de seu país, que chega a mais da metade das cadeiras do Parlamento (STAYCEY, 2013).Tal resultado surgiu a partir das eleições parlamentares de 2008, quando as mulheres chegaram a compor $56,3 \%$ das cadeiras parlamentares, enquanto que a média mundial na época era de 18\% (UN Coherence \& You, 2010). A nível global, as mulheres ainda são discriminadas e sub representadas em posições de liderança em qualquer esfera pública. A atual média mundial de participação feminina no parlamento, de acordo com dados da ONU (Women in Politics 2015), é de 22\%.

Tal situação ocorre mesmo diante do direito de participação igual em sociedades ditas democráticas, por exemplo. Essa discrepância entre participação feminina e masculina é fruto de uma cultura patriarcal enraizada, que não valoriza a capacidade feminina como equivalente à capacidade masculina. Ainda por ser uma variável pouco trabalhada, mas também por ser alvo de discussões mais recentes, o tema gênero chama a atenção na medida em que atua na percepção das diferentes relações de poder entre homens e mulheres. Nesse sentido, o exemplo prático de Ruanda aborda temas marginalizados no campo de estudo acadêmico das Relações Internacionais.

Partindo deste ponto de vista, estudar as mulheres envolve também estudar os homens, dado que ambos coexistem no sistema, e anular um em detrimento do outro implica desconsiderar as influências inerentes dessa relação (SCOTT, 1986, p. 1053). Como afirma Scott, o termo gênero implica numa construção social, em definições do que é masculino, do que é feminino e nas relações assimétricas de poder "que são confirmadas e construídas na economia e na política através das várias estruturas institucionais que tem o efeito de naturalizar e até mesmo legalizar o status da mulher como inferior" (SCOTT, 1986, p. 1053).

Durante a transição social no pós-genocídio, Ruanda passou pela adoção de novas medidas que foram criadas para incentivar a participação feminina nas estruturas de liderança em diferentes níveis, uma vez que foram responsáveis por boa parte da reconstrução do país. Depois de fazer um plano estratégico, desenvolvidos em meados de 2005(UN Coherence \& You, 2010)por meio da Política Nacional de Gênero (Republic of Rwanda, 2010), o país revelou se preocupar com a melhora das questões referentes ao gênero através da preparação e construção de um suporte institucional e organizacional que permitisse uma prática política 
mais igualitária. Assim, Ruanda aparece em destaque com seus 63.8\% de participação feminina nos parlamentos. Por se tratar de um país considerado pouco desenvolvido, por pertencer a um continente 'colonizado', é raramente lembrado como um emblemático exemplo nas discussões sobre o tema, sendo este caso importante na medida em que promove a revisão e questionamento de tais preconceitos. Nesse sentido, a participação política das mulheres torna-se um indicador chave do qual a Comunidade Internacional se serve para medir a boa governança e o processo de democratização.

O presente artigo irá utilizar documentos oficiais de Ruanda, artigos e fontes eletrônicas como o Fórum EconômicoMundial, ONU, dados do Banco Mundial, Gender Index. Primeiramente, foifeita uma seleção de leituras e fichamentos a partir das análises documentais realizadas. Tal método proporciona uma grande quantidade de informações pois permite a ampliação do entendimento do objeto estudado, levando em consideração a contextualização histórica e sociocultural do fenômeno além de permitir observar a evolução do comportamento político nas questões de gênero do país (CELLARD, 2008).

Além disso, o trabalho pode ser caracterizado como uma pesquisa exploratória de caráter descritivo pois objetiva se familiarizar com o fenômeno estudado, buscando novas percepções e traçando elementos a partir de um estudo de caso. Nesse sentido, foram utilizadas evidências quantitativas catalogadas, dados estatísticos, pesquisas, comparações junto a abordagem qualitativa,usando de narrações, ilustrações, trabalhando tanto com base na história do país quanto com as situações mais contemporâneas a fim de descrever a realidade de modo mais complexo.Por dar maior liberdade e amplitude de trabalho, o estudo de caso será utilizado uma vez que o trabalho se propõe a compreender "como" e "por que" um fenômeno específico acontece.

Após o genocídio de 1994, as mulheres passaram a compor a maioria da população, sendo levadas a trabalhar e a assumir papeis de liderança. E nesse sentido, tal acontecimento foi sendo firmado ao longo dos anos, reforçando essa inclusão desde a modificação do sistema educacional até o próprio empoderamento social feminino no cotidiano. Com isso, visto a crescente luta das mulheres, a participação política das ruandesas tem sido promovida pela nova Constituição, que vem gerando cotas como um reflexo da sensibilidade para com as questões de gênero e inclusão, aliados ao apoio de uma série de aparatos institucionais que garantem o espaço e o preparo destas mulheres.

As perspectivas feministas vão questionar a estrutura desigual das sociedades (MIGUEL, L. F.; BIROLI, 2014, cap. 7). Com isso, Biroli indaga, por exemplo, se para promover uma sociedade mais igualitária, em termos de gênero, bastaria insistir apenas nas 
discussões acerca dos valores de uma sociedade e da compreensão dos papeis de gênero, oué preciso ir além, propondo algo que resultasse efeitos mais concretos? Nesse caso, há uma preocupação política acerca da igualdade de gênero que foi incorporada pela própria constituição ruandesa bem com ratificado nos instrumentos internacionais. Portanto, aqui o objetivo é traçar o progresso da questão da igualdade de gênero desde a independência do país, destacando elementos que foram essenciais para os resultados ótimos mais recentes do período pós-genocídio.

Tal estudo trará maior lucidez e informações a respeito de um Estado marginalizado, pertencente ao continente africano, procurando mostrar o empoderamento na esfera pública e privada das mulheres ruandesas, trazendo as abordagens feministas das Relações Internacionais à frente dessas discussões. Assim, o estudo procura repensar a relação entre democracia e os bons indicadores de igualdade de gênero que tradicionalmente estão coadunados no campo de estudo das Relações Internacionais além de analisar o crescimento da inclusão feminina na tomada de decisão no país.

\section{Analisando o Caso de Ruanda à Luz dos Estudos de Gênero}

\section{Panorama das Abordagens Feministas}

Segundo Sylvester as perspectivas feministas chamaram atenção logo quando surgiram na década de 1980, não obstante, continuam recebendo pouca atenção na esfera da política internacional (SYLVESTER, 1994). Por isso a importância de insistir cada vez mais em novos estudos que agreguem à estas perspectivas, validando-as enquanto categoria de análise. E por se tratar de uma abordagem recente, muito diversa e ampla no campo de estudo das RI é possível identificar muitas dificuldades em aceitar a legitimidade de tal perspectiva na qual a identidade de gênero - abordagem até então não reconhecida pelas teorias dominantes -, torna-se o centro das discussões (NOGUEIRA, s.d., p.222). De acordo com Scott,

No seu uso recente mais simples, "gênero" é sinônimo de "mulheres". Durante os últimos anos, livros e artigos que tinham como tema a história das mulheres, substituíram em seus títulos o termo "mulheres" pelo termo "gênero". [...] Nessas circunstâncias, o uso do termo "gênero" visa indicar a erudição e a seriedade de um trabalho, pois "gênero" tem uma conotação mais objetiva e neutra do que "mulheres". O gênero parece integrar-se à terminologia científica das ciências sociais e, por consequência, dissociar-se da política (pretensamente escandalosa) do feminismo (SCOTT, 1986). 
A partir da década de 1990 alguns eventos aconteceram revelando crescente violência contra as mulheres no âmbito internacional. Isto é, mulheres sendo vítimas apenas por serem mulheres. Com isso, a academia teve sua atenção voltada a necessidade de se falar sobre as relações de poder a partir dos termos de gênero. Scott ainda afirma que

\begin{abstract}
Gênero" como substituto de "mulheres" é igualmente utilizado para sugerir que a informação a respeito das mulheres é necessariamente informação sobre os homens, que um implica no estudo do outro. Este uso insiste na idéia de que o mundo das mulheres faz parte do mundo dos homens, que ele é criado dentro e por esse mundo. Esse uso rejeita a utilidade interpretativa da idéia das esferas separadas e defende que estudar as mulheres de forma isolada perpetua o mito de que uma esfera, a experiência de um sexo, tem muito pouco ou nada a ver com o outro sexo. Ademais, o gênero é igualmente utilizado para designar as relações sociais entre os sexos. $\mathrm{O}$ seu uso rejeita explicitamente as explicações biológicas, como aquelas que encontram um denominador comum para várias formas de subordinação no fato de que as mulheres têm filhos e que os homens têm uma força muscular superior (SCOTT, 1986).
\end{abstract}

De início, as teorias construtivistas tiveram grande participação na consolidação das perspectivas feministas, que através dos seus instrumentos analíticos, conseguiram permear o campo das Relações Internacionais levando o debate à questão da identidade e das instituições. Além disso, trouxe também o conceito de construção social, na qual as feministas convergem no sentido de que o gênero não é predeterminado, mas sim, socialmente construído ((NOGUEIRA, s.d., p.625). Ainda de acordo com Scott

\footnotetext{
Os(as) historiadores(as) feministas utilizaram toda uma série de abordagens na análise do gênero, mas estas podem ser resumidas em três posições teóricas. A primeira, um esforço inteiramente feminista que tenta explicar as origens do patriarcado. A segunda se situa no seio de uma tradição marxista e procura um compromisso com as críticas feministas. A terceira, fundamentalmente dividida entre o pós-estruturalismo francês e as teorias anglo-americanas das relações de objeto, inspira-se nas várias escolas de psicanálise para explicar a produção e a reprodução da identidade de gênero do sujeito (SCOTT, 1986).
}

Sobre o descaso da academia de Relações Internacionais com o estudo de gênero, Tickner ressalta que autores do mainstream dizem tratar de relações interpessoais entre homens e mulheres, mas não sobre Relações Internacionais. Além disso, diversos autores tradicionais afirmam que há uma ausência de contribuições por parte das feministas no que diz respeito aos temas da alta política, caracterizando-as como incapazes de resolver problemas reais (TICKNER, 1997, p. 615). Tais autores ainda alegam a neutralidade da disciplina, não enxergando os conceitos de gênero intrínsecos que permeiam todas as esferas da vida pública e privada (TICKNER, 1997, p. 614). Os estudos tradicionais, por exemplo, dizem garantir e defender a segurança de todos os cidadãos, sendo que esta política é discutida e definida apenas entre homens. Com isso, apesar de Ruanda apresentar quase dois 
terços do parlamento composto por mulheres, o caso de violência física contra a mulher já chegou a 56\% no país (USAID, 2010). Tal dado nos mostra que assuntos de segurança da alta política nem sempre conseguem solucionar casos de segurança doméstica, necessitando então de medidas internas a fim de incentivar a criação de políticas acessíveis que envolvam a população local, promovendo a segurança a fim de amenizar os recorrentes problemas de gênero. Sem isso, cria-se portanto, uma estrutura que gera insegurança nos cidadãos, cabendo a mulher ser agente de sua própria segurança (USAID, 2010, p. 625).

O patriarcado na verdade é um termo controverso ainda na própria teoria feminista, segundo Biroli

Para algumas autoras, trata-se do conceito capaz de 'capturar a profundidade,
penetração ampla (pervasiveness) e interconectividade dos diferentes aspectos da
subordinação das mulheres'. De maneira similar, Carole Pateman julga ser
necessário dar um nome unificador às múltiplas facetas da dominação masculina.
'Se o problema não tem nome, o patriarcado pode facilmente deslizar de novo para a
obscuridade, sob as categorias convencionais da análise política. Para outras
percepções dentro do próprio feminismo, porém, o patriarcado é entendido como
sendo apenas uma das manifestações históricas da dominação masculina. Ele
corresponde a uma forma espećfica de organização política, vinculada ao
absolutismo, bem diferente das sociedades democráticas concorrenciais atuais
(MIGUEL; BIROLI, 2014, cap 1).

Acerca da categoria de análise, as feministas apresentam certo pluralismo epistemológico e ontológico, preferindo uma hermenêutica de base mais histórica e humanística em oposição às correntes tradicionais da disciplina. Além disso, são céticas no que tange ao empirismo metodológico, rejeitando a neutralidade dos fatos (USAID, 2010, p. 619). E apesar de gradativa, a inserção das feministas no campo acadêmico de Relações Internacionais ocidentais precedeu de dois momentos a sua conformação: a primeira geração, que lutou pelo sufrágio e direito à participação das mulheres no espaço público, especificamente na política; e a segunda geração, que na década de 1970 surgiu com uma nova agenda demandando sua inclusão social (NOGUEIRA; MESSARI, 2005, p. 224). A partir da terceira geração, o movimento finalmente toma forma e se estrutura de modo a se ajustar à disciplina das RI.

É importante também considerar a conexão entre os graus de abertura dos regimes políticos e o controle dos gêneros. Scott afirma que dirigentes emergentes legitimam a dominação, a autoridade e a força como características pertencentes ao "homem", sendo o contrário, a fraqueza e a subversão, relacionados à "mulher" (SCOTT, 1986, p. 1071). Esta simbologia presente na linguagem acabou permeando as práticas jurídicas e constitucionais, enraizados nas sociedades ocidentais, a partir da proibição da participação da mulher na vida política, coibição dos trabalhos dignos e igualitários, e imposição de códigos de conduta na 
tentativa de enquadrar a mulher no que diziam ser o seu lugar. Dessa forma, entende-se que “essas ações só podem adquirir um sentido se elas são integradas a uma análise da construção e da consolidação do poder.” (SCOTT, 1986, p. 1072).

Um exemplo parte dos teóricos políticos do Iluminismo que eram muito explícitos quando afirmavam que a mulher não era capaz e não deveria ser encorajada a conquista da autônoma e da racionalidade. O expoente filósofo, Kant, acreditava no desenvolvimento da racionalidade como meio de prosperar e formar o caráter moral; no entanto, sua tese se limitava ao ponto em que nega a capacidade feminina de conquistar tais proezas. Também foi de encontro à educação das mulheres, tendo como justificativa a inibição do desenvolvimento dos homens (TICKNER, 1997, p.617).

As dicotomias hierarquizantes são constantemente ratificadas pela própria sociedade ao longo dos anos, como racional/irracional, universal/particular, público/privado, resultando na legitimação do que é percebido como trabalhos racionais (política, economia e justiça) na forma que desvaloriza as atividades "naturais" (cuidados com a casa, com as crianças), confirmando a ideia da mulher associada aos cuidados da vida privada, impossibilitando sua inserção na esfera pública (TICKNER, 1997, p. 621). Assim, como afirma Biroli, as desigualdades estruturais impactam as possibilidades de auto definição, limitando as oportunidades disponíveis para os indivíduos.

No que tange o tema da educação feminina em Ruanda, 97\% delas vão para a escola primária, no entanto, menos de 13\% frequentam o ensino secundário (Rwanda Girls Initiative, s.d.). E por causa das dificuldades em conseguir entrar em boas escolas do secundário devido às altas exigências, muitas meninas encontram limitações ainda maiores por causa das responsabilidades domésticas e outras preocupações de segurança, obstaculizando seu desempenho acadêmico (Rwanda Girls Initiative, s.d.). Assim:

A construção da democracia corresponderia, numa abordagem que busca justamente avançar na politização da teoria política, ao enfrentamento de dois problemas de primeira ordem: a redução da subordinação e a criação de uma sociedade mais democrática. Em outras palavras, seria preciso recolocar o foco na conexão entre "as relações de subordinação civil e os problemas referentes à autonomia e à democratização”. Mas para isso, é necessário desnaturalizar o direito de alguns de governar outros, seja por meio do emprego, seja por meio do casamento ou de outros arranjos nos quais as relações de gênero se definem por assimetrias de recursos e de autoridade (em geral, pela complementariedade entre as duas)(MIGUEL; BIROLI, 2014, cap. 7).

Portanto, é preciso discutir a divisão sexual do trabalho a partir da ótica da autonomia exercida pelos homens e mulheres. Desde a juventude, as mulheres se deparam com distintas realidades que partem da linguagem à própria imposição de padrões de conduta que deveriam 
seguir, e por isso, apresentam acesso diferenciado à gerência do tempo e também aos recursos, devido, muitas vezes, às experiências de jornada dupla de trabalho na qual se dedicam à gestão das atividades privadas mais intensamente que os homens. Biroli então esclarece que:

\begin{abstract}
Quanto menores são os recursos e os mecanismos públicos para apoiar indivíduos e famílias na tarefa de cuidar dos dependentes, maior é o impacto da dedicação a essa tarefa no exercício de outras atividades, sobretudo daquelas remuneradas, e na construção de carreiras profissionais. Essa questão é central à análise crítica da privatização dos problemas definidos como familiares e das desigualdades que daí decorrem. [...] As desvantagens se acumulam, produzindo maior vulnerabilidade $\mathrm{e}$ dependência. (MIGUEL; BIROLI, 2014, cap. 7)
\end{abstract}

Em nossa história mais recente, o "regime democrático tem construído suas ideologias políticas por meio de conceitos de gênero, gerando políticas concretas, como o Estado de Bem-Estar Social, que demonstrou seu paternalismo protetor por meio de leis direcionada às mulheres e crianças." (SCOTT, 1986). Fazendo um paralelo com o caso estudado, vemos que é possível mudar tal conjuntura. Ruanda, apesar dos seus baixos indicadores - como 0,48 de IDH (KNOEMA, 2014) e baixo índice de democracia (KNOEMA, 2015) -, conseguiu impulsionar a participação de suas mulheres na vida pública, gerando impacto nos estudos de igualdade de gênero. Esta pesquisa objetiva problematizar as antigas definições de gênero para o país e a identificar possíveis influências da vida privada/pública, que as guiaram em direção à uma firme participação política e à uma maior visibilidade. Scott ainda afirma:

\footnotetext{
Tais pensamentos contribuem no sentido de abrir portas para novos pensamentos sobre as estratégias políticas feministas atuais e posterioresporque ela sugere que o gênero tem que ser redefinido e reestruturado em conjunção com uma visão de igualdade política e social que inclui não só o sexo, mas também, a classe e a raça (SCOTT, 1986).
}

Por fim, é importante sempre rever a história, procurando questionar os aspectos tradicionais, tanto por meio das experiências subjetivas como também das atividades públicas e políticas (TICKNER, 1997). Finalmente, a análise, motivada pela observação do aumento da participação feminina na política em Ruanda, visa gerar um debate sobre a necessidade de se tratar de assuntos que envolvem gênero relacionados ao desenvolvimento do Estado. Com o estudo da participação das mulheres ruandesas nos âmbitos público e privado, será possível interpretar com base nas óticas feministas das RI, como se configuram os fundamentos que possibilitam tal desempenho no país, a fim de problematizar aspectos fundamentais, como o seu comportamento político na formulação de estratégias para a promoção da igualdade de gênero e, por conseguinte, do desenvolvimento social. E como sugere as perspectivas feministas, é preciso insistir nos debates que tenham o gênero como centro, considerando que 
a compreensão do tema é a melhor forma de superar preconceitos e a ausência de diálogos, buscando construir algo mais sólido para as gerações futuras.

\section{Importância dos Estudos de Gênero em Ruanda}

Apesar de todo esse impulso em implantar um panorama de igualdade de gênero, o país ainda precisa de muitos avanços em diferentes esferas da sociedade. A desigualdade de gênero em Ruanda ainda é um problema aparente na vida privada. No quesito educação, as mulheres apresentam 97\% de participação na educação primária, enquanto que, no ensino secundário, este número cai para 13\% (Rwanda Girls Intiative, s.d.). Como consequência, as ruandesas se deparam com maiores limitações devido às altas exigências do ensino superior, que junto às atividades da gerência doméstica -ocupação majoritariamente feminina -, as mulheres acabavam desistindo de continuar os estudos (Rwanda Girls Intiative, s.d.).

Segundo Scott, gênero é um elemento constitutivo das próprias relações sociais que são fundadas sobre as divergências percebidas entre os sexos, além de ser também, um modo primordial de dar valor e significado às relações de poder (SCOTT, 1995). Para a teórica feminista, essas duas proposições estão intrinsecamente relacionadas. As mudanças na organização das relações sociais correspondem sempre às mudanças nas representações de poder. No entanto, a direção dessa mudança não segue necessariamente um único sentido (ARAÚJO, 2005).

As diferenças entre os sexos está presente desde os primórdios em distintos discursos ao longo da história. No entanto, apenas na modernidade foi possível notar a real importância dos estudos de gênero, sendo este um novo objeto de análise. Assim, estudar as mulheres quer dizer estudar também os homens, uma vez que ambos coexistem no sistema, e anular um em detrimento do outro implica desconsiderar as influências inerentes dessa relação (SCOTT, 1986).

Com crescente aumento da violência contra as mulheres a partir da década de 1990, maior atenção foi voltada a necessidade de se falar sobre as relações de poder a partir dos conceitos de gênero (NOGUEIRA, 2005, p. 222). Historicamente, o conceito de gênero busca encontrar as maneiras pelas quais o mesmo se legitima e se constrói nas relações sociais. Em sua compreensão, é importante saber em qual contexto surge, já que provem de construções sociais na qual a política e o gênero se co-constituem,dando um enfoque adequado ao caso (NOGUEIRA, 2005, p. 222). Nesse caso, a política pode servir como base para uma análise 
histórica, apresentando as questões de gênero como seu objeto de estudo. Segundo Biroli e Miguel,

\begin{abstract}
As desigualdades entre homens e mulheres é um traço presente na maioria das sociedades, se não em todas. Na maior parte da história, essa desigualdade não foi camuflada nem diferenciada dos dois sexos; pelo contrário, foi assumida como um reflexo da natureza diferenciada dos dois sexos e necessária para a sobrevivência e o progresso da espécie. Ao recusar essa compreensão, ao denunciar a situação das mulheres como efeito de padrões de opressão, o pensamento feminista caminhou para uma crítica ampla do mundo social, que reproduz assimetrias e impede a ação autônoma de muitos de seus integrantes (MIGUEL; BIROLI, 2010).
\end{abstract}

A oposição binária igualdade/diferença também é discutida por Scott, que defende a desconstrução do mesmo. Tal oposição binária, teorizada por Derrida, conduz uma discussão no sentido de que a mesma obscurece a interdependência dos dois termos, uma vez que a igualdade não significa a ausência de diferença e a mesma não impede a igualdade (SCOTT, 1986). Assim, é possível dizer que os seres humanos nascem iguais perante a lei, mas diferentes entre si, e que essa igualdade reside na diferença. Deste modo, surge uma nova diferença, a diferença múltipla, como uma alternativa ao binômio da igualdade/diferença (ARAÚJO, 2005, p.46).

Nos primeiros passos do movimento feminista, a luta pela igualdade ficou mais latente. Apenas com os estudos mais recentes, pós década de 70 que o debate se centrou nas questões dessas diferenças. De acordo com os debates subsequentes, "passou-se então a falar de diferença cultural, cultura feminina, experiência feminina, reconhecimento da diversidade cultural de gênero e assim por diante." (ARAÚJO, 2005, p.46). Foi depois disso que instituições internacionais incorporaram esses pensamentos e promoveram os debates sobre gênero trazendo novas perspectivas.

A importância desses estudos se dá pelas relações desiguais que se consagram nas sociedades patriarcais. Ao longo da história,

\begin{abstract}
Identifica-se uma maior apropriação pelos homens do poder político, do poder de escolha e de decisão sobre sua vida afetivo-sexual e da visibilidade social no exercício das atividades profissionais. Este é um processo que resulta em diferentes formas opressivas, submetendo as mulheres a relações de dominação, violência e violação dos seus direitos. Poder e visibilidade são construtos históricos, determinados na e pelas relações sociais. Em cada conjuntura sócio histórica é preciso, portanto, analisar os elementos de determinação do ponto de vista econômico, político e cultural que incidem na vida cotidiana dos indivíduos e estruturam valores, modos de pensar, de ser e agir. Ou seja, trata-se não apenas de reconhecer quem tem poder e visibilidade, mas em quais condições materiais foram alicerçados e são efetivados. (SANTOS; OLIVEIRA, 2010, p. 12)
\end{abstract}

Nesse sentido, para entender o recente empoderamento feminino em Ruanda no período pós genocídio, é importante, primeiro, entender como essas relações sociais são 
percebidas e efetivadas entre os indivíduos de uma determinada sociedade, analisando suas idiossincrasias, como elas se organizam e como observam seus próprios valores, direitos e poderes na vida social.

Portanto, as perspectivas feministas atuam nos aspectos do patriarcado, isto é, sistema de dominação masculina referentes às relações de poder e consequente subordinação feminina, e de como estas foram transformadas e construídas historicamente (SANTOS; OLIVEIRA, 2010, p. 14), influenciando os movimentos e estudos feministas em todo o mundo. É justamente nessa cultura patriarcal que o incipiente governo ruandês irá implementar um modelo de cotas femininas, visando uma política de mudança estrutural sustentável a longo prazo a fim de promover a igualdade e justiça para as mulheres. Assim, os estudos de gênero são importantes na medida em que irão promover a conscientização do mundo à respeito da discriminação feminina, como vem acontecendo em Ruanda apesar das mudanças identificadas.

\section{Participação Feminina na Política em Ruanda}

Depois da independênciada Bélgica em 1961, as mulheres de Ruanda conquistaram o direito ao voto. A primeira mulher parlamentarista começou a servir em 1965. No entanto, antes da guerra civil, ainda no começo da década de 1990, as mulheres ruandesas não conseguiram mais do que $18 \%$ dos assentos parlamentares (INTER PARLIAMENTARY UNION, 1995).

O genocídio de 1994 em Ruanda marcou uma violenta luta entre os hutus contra a minoria tutsi, destruindo a infraestrutura do país e perpetuando a pobreza e destruição junto à uma população traumatizada (POWLEY, s.d.). No pós genocídio, com o governo transicional, de 1994 a 2003, a representação feminina no parlamento alcançou 25.7\% e uma nova constituição foi adotada (POWLEY, s.d.). O aumento da participação feminina foi resultado dos novos mecanismos usados para incentivar a participação feminina que, por meio de garantia constitucional, conseguiu fixar um sistema de cotas e inovações eleitorais

O Artigo nono da Constituição de 2003 expõe algumas provisões interessantes e fundamentais a respeito dos Direitos Humanos. Um em particular é direcionado à eliminação de qualquer forma de discriminação contra a mulher, além de mencionar igualmente a importância da erradicação de divisões étnicas, regionais; a importância de um estado democrático pluralista justo na qual as mulheres devem ter garantia de, no mínimo, $30 \%$ das posições de liderança nos corpos políticos (RWANDA'S CONSTITUTION OF 2003, 2016). 
Ainda nos artigos 54, que nega a discriminação de qualquer tipo, afirmando a necessidade de incentivar a participação de todos nas organizações políticas; e o artigo 76 da Constituição, que exalta a necessidade da presença de 24 membros da Câmara dos deputados serem mulheres, as cotas são reafirmadas. É importante notar, no entanto que, embora a Constituição de Ruanda seja progressista em termos de igualdade de gênero, preocupações específicas foram levantadas sobre a liberdade de expressão e repressão dos partidos de oposição.

O Ministério de Gênero e Mulheres para o Desenvolvimento foi criado logo após o genocídio, tendo seu papel estendido em vários âmbitos (POWLEY, s.d.). Os conselhos das mulheres são estruturas de base eleitas por mulheres e por meio de eleições indiretas. Tais conselhos operam em paralelo aos conselhos municipais gerais e representam tudo o que concerne aos problemas relacionados às mulheres, (POWLEY, s.d.) como os casos de violência doméstica que ainda são persistentes no país, revelando a necessidade de serem discutidos nestes núcleos de representatividade feminina.

As parlamentares provenientes dos Conselhos das Mulheres em Ruanda ressaltam a importância deste sistema na medida em que, historicamente, as mulheres não podiam aparecer em público; isto é, onde os homens estavam, as mulheres não deviam se expressar; os homens deveriam falar e pensar por todos. Nesse sentido, a partir da criação dos Conselhos das Mulheres, mobilizações têm sido usadas como ferramenta no sentido de educar as mulheres, trazendo autoconfiança e proporcionando uma participação mais ativa (POWLEY, p. 157).

Portanto, apesar dos Conselhos das Mulheres serem importantes na medida em que promovem a descentralização e o engajamento de base, ainda há outros fatores que impedem a maximização desses impactos, como a falta de recursos. Muitas vezes, os membros dos comitês das mulheres locais não são pagos, e por isso, elas tem que se voluntariar. No entanto, as mulheres destes conselhos de base têm trabalhado com êxito, principalmente pós nova constituição de 2003 (POWLEY, p. 157).

Dessa forma, concomitantemente e junto a todo o aparato institucional, movimentações sociais surgiram e ONG's aproveitaram o desarranjo social e governamental do período do pós genocídio para promover uma variedade de serviços necessários à reconstrução do país traumatizado pelo conflito. Assim, as mulheres se reuniram para formar uma organização conhecida como Pro-Femmes, responsável por coordenar diversas outras organizações que tem agido com êxito nas atividades relacionadas às mulheres, aconselhandoas sobre os problemas da mulher no âmbito governamental, na participação política 
(POWLEY, s.d.) como o incentivo ao empoderamento das mulheres e a diminuição da discriminação, promovendo peacekeeping e outras mediações (MARILENA, s.d.).

Junto às organizações feministas, vários setores se empenharam em contribuir para a formulação de um novo documento político com o intuito de recomendar ações específicas para a Constituição mais sensível das questões de gênero submetido na Comissão Constitucional. No entanto, afirmou-se o impacto que os movimento Pro-Femmes tem causado na vida pública da sociedade. As Organizações não-governamentais das mulheres são o setor mais influente da sociedade civil ruandesa (USAID, 20??, p.37).

As parlamentares ruandesas formaram uma convenção política conhecida como Fórum das Mulheres Parlamentares, com fundos e apoios internacionais. Elas afirmam não pensar de acordo com os partidos políticos, mas sim, de acordo com suas demandas, necessidades e desafios que as cercam (SEKAMANA, 2002). Nesse sentido, o Fórum apresenta várias funções como revisão das leis, introdução de alteração às emendas discriminatórias, examina as proposições de leis com sensibilidade de gênero, mantém relações com o Movimento das Mulheres, conduz encontros e treinamento com organizações das mulheres a fim de sensibilizar a população, afirmando ser de sua responsabilidade a promoção dessa perspectiva de gênero no país.No entanto, um dos maiores empecilhos do país é a pobreza feminina. Violências de gênero também continuam a ser um forte problema sobretudo nas zonas rurais (USAID, 2010).

\section{Política em Ruanda}

\section{Democracia}

Reformas democratizantes ocorreram no continente africano após a Guerra Fria, já em 1989. Tal processo resultou numa modificação das estruturas políticas dos regimes africanos, implantando sistemas mais competitivos e pluralistas. Na década de 1990, grande parte dos países da África Subsaariana sofreram as influencias ocidentais da política neoliberal e dos processos de democratização (MINILLO, 2012, p.4). Os Estados acreditavam na associação da democracia com o desenvolvimento, além de perceberem a necessidade de promover a participação popular nos processos políticos, ressaltando os direitos humanos (MINILLO, 2012, p.5). Ruanda comprometeu-se com o processo de democratização ainda mais pela necessidade de reconstrução do país haja vista a destruição dele em 1994. 
De acordo com a autora Maria Lúcia da Silveira um Estado democrático visaria sobretudo a ampliação da cidadania (SILVEIRA, 2003). Emerge, durante os anos 1990, um momento difícil para as políticas de caráter universal e redistributivas. Nesse sentido, as políticas neoliberais impactaram negativamente as tentativas de dar um aspecto público ao Estado, implantando o Estado Mínimo além de políticas compensatórias (SILVEIRA, 2003). Tais mudanças impactaram também as mulheres que buscavam obter espaço na agenda política, a fim de construir políticas que melhorassem suas vidas públicas especialmente dentro dos setores populares, além da qualidade de vida. Ainda de acordo com a autora,

\footnotetext{
Resgatar as mulheres como sujeito das políticas, implica construir canais de debate para definir prioridades e desenhar estratégias para caminhar no sentido de transformar os organismos de políticas para mulheres nos governos democráticos em seus diversos níveis, federal, estadual e municipal em interlocutores válidos para construir as pautas políticas e articuladores gerais das políticas públicas prioritárias (SILVEIRA, 2003, p.5).
}

Tendo em mente que a democracia representativa é uma tradição ocidental, as atitudes em relação à representação e os deveres dos representantes podem diferir num contexto não-ocidental onde as tradições democráticas são consideravelmente mais recentes e menos profundas. Também há a questão do impacto que o uso da cota teve sobre a representação das mulheres no contexto africano, procurando saber se realmente há a representação dos interesses das mulheres como será discutido na próxima seção (SCHWARTZ, 2004). Isso nos leva a outra questão sobre como representar as mulheres uma vez que elas nem sempre partilham os mesmos interesses (MOROJELE, 2016, p. 34).

Em meio a contextos e experiências diferentes do dia a dia, as mulheres enfrentam realidades distintas, mas todas partilham a mesma experiência da opressão do patriarcado. A autora Molyneux (1985), propõe que as mulheres partilham interesses como a abolição das divisões de trabalho com base no gênero, diferentes formas de discriminação dentro das instituições, as consideradas 'obrigações' dos serviços domésticos, violência doméstica, dentre outros. Essas seriam as necessidades e lutas imediatas (MOLYNEUX, 1985). Portanto, após observar medidas como a política de cotas, foi possível perceber mudanças reais nos indicadores por meio de uma agenda favorável às políticas de gênero que atuam em conjunto com os diferentes movimentos de mulheres com respaldo estatal.

Uma grande mudança também foi observada nas concepções culturais e sociais dos papeis de gênero a partir das repercussões do genocídio, constatando maior representação das mulheres na vida pública e em cargos políticos. Junto com as mudanças, houve também uma maior aceitação das mulheres em cargos de autoridade e de agentes independentes na esfera 
pública. Essa transformação na subjetividade política poderia preparar as mulheres para desempenhar um papel significativo no governo caso uma transição real para a democracia ocorresse no país (BURNET, 2008, p.1).

Em Ruanda, a nova Constituição, que se caracterizou por uma construção de consenso de bases, culminou no referendo em maio de 2003. Workshops para compartilhar experiências na implementação das cotas de gênero estão sendo mantidos apenas como parte de um processo de transição que visa a melhora da democracia no país. Tal evento foi seguido pela eleição presidencial em agosto, e logo depois, das eleições para a Assembleia Nacional em setembro do mesmo ano (MINILLO, 2012, p.6). Desta vez, a Assembleia Nacional passaria a apresentar um sistema político bicameral, isto é, a Câmara dos deputados e o Senado, empenhados em erradicar as dificuldades que impossibilitam a participação feminina na tomada de decisão (MINILLO, 2012, p.6).

No entanto, Ruanda apresenta baixo Índice de Desenvolvimento Humano, apenas 0,48,bem como baixo índice democrático (KNOEMA, 2015). Apesar disso, conseguiu repensar e desenvolver uma política que pensa gênero como fator primordial para o progresso da nação. No que tange a construção da democracia, esta encontra algumas dificuldades como a redução da subordinação e a criação de uma sociedade mais democrática. Toda a sociedade é imposta a um sistema estrutural de tratamento patriarcal que, na maioria dos casos, resulta na dependência das mulheres aos homens, permeando as desigualdades e vulnerabilidade dessa relação (MIGUEL, L. F.; BIROLI, F., 2014, cap. 7). Segundo os autores

O acesso a recursos e o reconhecimento do valor e da capacidade dos indivíduos para definir a própria vida variam segundo suas características e sua posição nas relações de poder, entre elas o gênero. Desigualdades estruturais impactam as possibilidades de autodefinição e as oportunidades disponíveis para as pessoas (MIGUEL, L. F.; BIROLI, F., 2014, cap. 7).

No que tange às oportunidades empregatícias em Ruanda, a situação atinge maiores disparidades. Atualmente as mulheres sustentam $34.6 \%$ dos empregos do setor público comparado com $65.4 \%$ dos homens (TRIPP, 2004, p. 97). As mulheres acabam se concentrando sumariamente nos setores agrícolas, sendo a grande parcela desses trabalhadores. Considerando a discriminação ainda existente, as mulheres sofrem ainda mais para conseguir o direto às terras e o acesso ou controle de certos insumos necessários ao seu trabalho (TRIPP, 2004, p. 97).

\section{Política de Cotas}


Muitos países tem chamado a atenção devido à implementação de novas políticas de gênero em suas sociedades, e de como isso afetou diretamente seus índices de igualdade. Como ponto de partida, Ruanda servirá de exemplo por se tratar de um caso de sucesso no continente africano em termos de igualdade de gênero.

Em 2003, apenas 15,2\% dos membros parlamentares do mundo eram mulheres,(TRIPP, 2004, p. 16), dado que neutraliza a forte discrepância existente entre as diferentes regiões. Os países nórdicos ostentavam os melhores índices, enquanto que os países árabes possuíam os piores, e a África se posicionava próximo à média mundial, não passando de 15\%(TRIPP, 2004, p. 16).

Nas últimas duas décadas, o continente africano vem experimentando o crescimento dos níveis de igualdade de gênero no que tange a representação política feminina nos parlamentos. Ruanda se destaca com 63.8\%, ao lado de Senegal com 42.7\%, África do Sul com 41.4\% e Moçambique com 39.6\%, estando entre os 15 primeiros lugares do ranking da participação feminina no parlamento de acordo com os levantamentos da UN Women de 2015 (WOMAN IN POLITICS, 2015). Este rápido crescimento é fruto da implementação da política de cotas em muitos desses países.

A princípio, a maioria dos governos apoiam a ideia de balança de gênero na esfera política. Com a implementação das cotas, é possível observar uma melhora real na participação feminina na política, além de ser considerado uma forma legítima de estabelecer a igualdade de oportunidades em muitos países (POWLEY, 2003). Mesmo assim, existem controvérsias nos debates. As posições contrárias à política de cotas afirmam que esta é só mais uma forma de perpetuar a discriminação e de violar o princípio da justiça (POWLEY, 2003). No entanto, a real questão desta política é apostar num modelo que vise o equilíbrio das diferenças de oportunidade entre os sexos, procurando compensar algumas barreiras estruturais do sistema patriarcal e estimular uma participação mais balanceada.

Como afirma Biroli, a crítica feminista surge com o intuito de analisar a suspensão das relações de poder na esfera privada. Se reconhecermos as barreiras que as mulheres encontram na esfera privada, por exemplo - que as impedem de participar da vida política -, as cotas irão surgir como meio de promover a igualdade, a justiça e a compensação de diferenças. Assim que parte desses impedimentos forem removidos ao longo do tempo, as cotas não serão mais necessárias, pois as estruturas da sociedade já teriam sido modificadas (MIGUEL; BIROLI, 2014). Portanto, estas seriam metas temporárias, podendo levar bastante tempo até que sejam naturalizadas em determinadas sociedades. 
Os responsáveis por coordenar este cenário político são os próprios partidos que muitas vezes controlam o processo de nomeação (POWLEY, s.d., p. 95). Mulheres tem demandado metade dos assentos nos comitês de nomeação e dentro do partido que lidera a fim de influenciar o processo decisório. A decisão entre introduzir ou não as cotas no sistema entra, muitas vezes, na discussão sobre as influencias das pressões e recomendações internacionais, e pelo desenvolvimento em diferentes contextos nacionais. Muitas dessas políticas de gênero estão sendo implementadas principalmente em países com histórico de exclusão feminina na política, bem como Estados com maior proporção feminina na qual possuem papel fundamental (POWLEY, s.d., p. 95).

Antes das cotas, apenas $25,7 \%$ das mulheres ostentavam assentos parlamentares (TRIPP, 2004). Nesse sentido, as cotas devem ser introduzidas em países preocupados com um sistema político democrático, independentemente se são sistemas com liberdade democrática limitada, ou, até mesmo autoritárias, já que o objetivo seria promover um bom índice de governança nacional (TRIPP, 2004, p.96). Alguns sistemas de cotas são construídos com base neutra de gênero, isto é, corrigindo a sub-representação de ambos homens e mulheres. A cota de 50 por 50 é, naturalmente, uma neutralidade de gênero(TRIPP, 2004). Nesse caso, a ideia seria de que 'uma 'quota dupla' não só exige uma certa proporção de mulheres em uma lista eleitoral, mas também impede que as candidatas sejam colocadas no final da lista com poucas chances de serem eleitas" (IDEA, 2004, p. 98).

O sistema eleitoral tem uma forte relação com a representação política da mulher, em média, países com o sistema de representação proporcional ${ }^{2}$ são mais relacionados com as melhores médias, muitas vezes com o dobro da representação se comparado com outros sistemas políticos (IDEA, 2004, p. 98). As políticas de cotas são utilizadas em 21 países africanos, dos quais, duas categorias são principais: os assentos reservados às mulheres ou nomeações; e as quotas voluntárias do partidos (IDEA, 2004, p. 98). Outro fator crucial foi a mobilização das mulheres e recomendações das organizações regionais e internacionais na luta pela promoção das cotas. De acordo com a Kanakuze, "a vontade política dos líderes partidários é fundamental para o êxito da implementação das cotas.” (IDEA, 2004, p.98). Contudo é preciso maiores informações a fim de ter propriedade sob os efeitos das cotas no que tange a possível condução das mulheres ao empoderamento.

\footnotetext{
${ }^{2}$ No entanto, segundo Bobbio, "A representação proporcional [...], atribui ao partido um papel excessivo que obstaculiza a relação eleitor-representante, e, manipulando as designações dos candidatos, limita a vontade do eleitorado." Para saber mais ver: BOBBIO, Norberto, MATTEUCCI, Nicola e PASQUINO, Gianfranco. Dicionário de Política. São Paulo: Editora UNB - Imprensa Oficial: 2004. BURKE, Peter.
} 
Sobre o partidos políticos no país, a Frente Patriótica Ruandesa opera atualmente junto à coalizões, e tem feito o empoderamento das mulheres um dos seus marcos principais, incluso nos seus programas pós-genocídio de reconstrução (Rwandan Government, 2001). Como parte do novo modelo de governança, o ponto 3.3.4 do Plano de Estratégia Nacional promovido em março de 2002, o governo reconhecia que, para haver uma sociedade mais participativa, seria necessário a implementação de igualdade e equidade de gênero (Republic of Rwanda, 2002, p. 26). Para tal, algumas estratégias foram implantadas como a promoção da educação feminina, a participação feminina na tomada de decisão e outros processos estruturais.

A decisão do Governo de incluir a mulher na governança do país foi baseado em diversos fatores. Tal envolvimento proporcionou-lhes uma plataforma para defender a inclusão das mulheres durante a fase de transição, além de consolidar seus ganhos com a nova Constituição (POWLEY, p. 159).

\section{Conclusão}

A partir do desenvolvimento das perspectivas feministas em um estudo de caso acerca de políticas africanas, o debate tomou forma e ganhou espaço nas estruturas reais de alguns governos. Com este artigo, foi possível identificar alguns desafios e conquistas da participação feminina ao longo desse processo de modificação estrutural das políticas governamentais ruandesas, que por meio de instrumentos políticos, convenções e movimentos organizados, conquistaram seu espaço, lutando pela igualdade e equidade junto à sociedade civil.

Num país democrático, desentendimentos sobre as políticas implantadas são recorrentes, como no caso do sistema de cotas para as mulheres. Tais controvérsias se estabelecem principalmente por se tratar de uma política recente, cabendo continuar com os debates sobre sua implicação para a democracia e desenvolvimento de Ruanda.

Por fim, as mulheres enfrentam dificuldades que vão além do que se é percebido na esfera privada. Estes problemas também se inserem no próprio âmbito de sua representação, tais como a diferença das mulheres que entram na política por meio das cotas e das que entram pela ampla concorrência. Ainda é preciso superar estereótipos sobre as suas capacidades e competências como líderes.

É inegável que houve avanço na agenda feminista nos últimos anos, no entanto é imprescindível continuar a luta por uma mudança social mais profunda e inclusiva. Tal processo acontece de modo gradual, mas que se bem executado será de grande valor para a 
sociedade ruandesa, servindo de modelo para os estudos de gênero e influenciando o mundo pela promoção de maiores níveis de igualdade e justiça.

\section{Referências Bibliográficas}

ARAUUJO, Maria de Fátima. Diferença e Igualdade nas Relações de Gênero:revisitando o debate. Pisc. Clin., Rio de Janeiro, vol. 17, n.2, p.41 - 52, 2005.

BOBBIO, Norberto, MATTEUCCI, Nicola e PASQUINO, Gianfranco. Dicionário de Política. São Paulo: Editora UNB - Imprensa Oficial: 2004. BURKE, Peter.

BURNET, Jennie. Gender Balance and the Meaning of Women in Governance in Post-Genocide Rwanda.Georgia State University, 2008 P.1.

CELLARD, A. A análise documental. apud POUPART, J. et al. A pesquisa qualitativa: enfoques epistemológicos e metodológicos. Petrópolis, Vozes, 2008.

CONSOLEE, Uwihangana. Women's Rights and the Well-being of the Rwandan Family. University of Gothenburg, 2014. Disponível em: < https://gupea.ub.gu.se/bitstream/2077/36131/1/gupea_2077_36131_1.pdf>

DEVLIN, Claire; ELGIE, Robert. The Effect of Increased Women's Representation in Parliament: The Case of Rwanda. Pariamentary Affairs Vol. 61. No. 2, 2008, p. 237-254.

GASAMAGERA, Wellars. The Constitution Making Process in Rwanda: Lessons to be Learned.Junho 2007. Disponível em: http://unpan1.un.org/intradoc/groups/public/documents/un/unpan026620.pdf>

GENDER EQUALITY, UN Coherence \& You. Case Study. Delivering as One on Gender in Rwanda.Último acesso em 23/10/2016. Disponível em: <http://www.unicef.org/gender/training/content/resources/Case_Study_Rwanda.pdf

HOGG, Nicole. Women's Participation in the Rwandan genocide: mothers or monsters. Volume 92 Number 877 March, 2010. Disponível em: < https://www.icrc.org/eng/assets/files/other/irrc-877-hogg.pdf >

Inter-Parliament Union (IPU), 2008. Equality in Politics: A Survey of Woman and Men in Parliaments.Reports and Documents $\mathrm{N}^{\circ}$ 54. Disponível em: <http://www.ipu.org/pdf/publications/equality08-e.pdf>

Inter-Parliamentary Union (IPU), 1995. Women in Parliaments1945-1995: A World Statistical Survey. Geneva: IPU

KANAKUZE, Judith. Personal interview, Julho 2003 Apud POWLEY, Elizabeth, 2003. Strengthening Governance: The Role of Women in Rwanda's Transition. Washington, DC: Women Waging Peace; e Powley, Elizabeth, 2005.

KNOEMA. Atlas Mundial de Dados. Índice de Democracia. 2015. Disponível em: < http://pt.knoema.com/atlas/Ruanda/\%C3\%8Dndice-de-democracia> 
KNOEMA. Atlas Mundial de Dados. Índice de Desenvolvimento Humano. 2014. Disponível em: <http://pt.knoema.com/atlas/Ruanda/\%C3\%8Dndice-de-DesenvolvimentoHumano>

MIGUEL, L. F.; BIROLli, F. Autonomia, Dominação e Opressão. Apud Feminismo e política: uma introdução. São Paulo: Boitempo, 2014 Cap. 7.

MIGUEL, Luis Felipe; BIROLI, Flávia. Feminismo e Política: O Público e o Privado. São Paulo: Boitempo, 2014.

MINILLO, X. K. A Importância do estudo das relações internacionais africanas para o campo das Relações Internacionais. Revista Monções. Vol. 1. N. 1. 2012.

O Estado da cultura Liberal-Democrática na África. $1^{\circ}$ Seminário Nacional de Pós-graduação em Relações Internacionais Associação Brasileira de Relações Internacionais Brasília, 12-13/07/2012.

MOLYNEUX M. Mobilization without Emancipation? Women's interests, the state, and revolution in Nicaragua. 1985.

MOROLEJE, Naleli. Women Political Leaders in Rwanda and South Africa: Narratives of Triumph and Loss. Barbara Budrich Publishers, 2016 p.34.

NOGUEIRA, João Pontes e MESSARI, Nizar. Teoria das Relações Internacionais; correntes e debates. Editora Campus, São Paulo, 2005. p. 222.

POWLEY, Elizabeth. Rwanda: The Impact of Woman Legislators on Policy Outcomes Affecting Children and Families. The State of The World's Children. 2007.

POWLEY, Elizabeth. Rwanda: Woman Hold Up Half the Parliament. Disponível em: < http://www.idea.int/publications/wip2/upload/Rwanda.pdf>

POWLEY, Elizabeth. Strengthening Governance: The Role of Woman in Rwanda's Transition a Summary. EGM/ELEC/2004/EP.5. Disponível em: < http://iknowpolitics.org/sites/default/files/strengthening20governance20-

20the20role20of20women20in20rwanda27s20tra.pdf>

REPUBLIC OF RWANDA. Ministry of Gender and Family Promotion. National Gender Policy. Final Version. 2010.

REPUBLIC OF RWANDA. National Strategy Framework Paper on Good Governance for Poverty Reduction in Rwanda. Ministry of Local Government and Social Affairs. Kigali, 2002.

RWANDA GIRLS INITIATIVE. Educate Girls in Rwanda. Disponível em: <http://rwandagirlsinitiative.org/educate_girls_rwanda>

RWANDA'S CONSTITUTION OF 2003 WITH AMENDMENTS THROUGH 2010. 2016. Disponível em: < www.constituteproject.org > 
RWANDAN GOVERNMENT, 'Good Governance Strategy Paper (2001)’, disponível em: $<$ http://www.

rwanda1.com/government/president/speeches/2001/strategygov.htm>último acesso em junho de 2018.

SANTOS, Silvana Mara Morais. OLIVEIRA, Leidiane. Igualdade nas relações de gênero na sociedade do capital: limites, contradições e avanços. Revista Katálisys.Florianópolis v. 13 n. 1, p. 11-19. 2010.

SCHWARTZ, Helle. Women's Representation in the Rwandan Parliament. An Analysis of Variention in the Representation of Women's Interests Caused by Gender and Quota. Suécia, 2004.

SCOTT, Joan W. A Useful Category of Historical Analysis. The American Historical Review, Vol. 91, No. 5. (Dec., 1986), p. 1053-1075.

SEKAMANA, Connie Bwiza, personal interview. Apud Powley, Elizabeth. 2002.

SILVEIRA, Maria Lúcia. Políticas Públicas de Gênero: Impasses e desafios para fortalecer a Agenda Política na Perspectiva da Igualdade. 2003.

SOMBRA SARAIVA, J. F. A África na ordem internacional do século XXI: mudanças epidérmicas ou ensaios de autonomia decisória? RBPI, vol 51, no. 1, 2008.

STACEY, Justine. Women's Empowerment and Development: The Contribution of Parliamentary Gender Quotas and the Case of Rwanda. Halifax, Nova Scotia, 2013.

TRIPP, Aili Mari, 2004. 'Quotas in Africa', in Julia Ballington (ed.). The Implementation of Quotas: Africa Experiences, Stockholm: International IDEA.

UNITED NATIONS RWANDA. Gender Equality.Disponível em: <http://www.rw.one.un.org/mdg/mdg3> último acesso em maio de 2018.

USAID/Rwanda. "Rwanda Demographic and Health Survey: 2000 - 2010." Ministry of Health, Kigali, 2010.

USAID. Rwanda Democracy and Governance Assessment. Management Systems International, 2002.

WOMEN'S COMMISSION FOR REFUGEE WOMEN AND CHILDREN.Rwanda's Women andChildren: The Long Road to Reconciliation.New York: Women's Commission 